\title{
The Mine Working's Roof Stress-strain State Research in the Perspective of Development of New Coal Deposits of Kuzbass
}

\author{
Svetlana Kostyuk ${ }^{1}$, Nikolay Bedarev ${ }^{2}$, Oleg Lyubimov ${ }^{1, *}$, and Arthur Shaikhislamov ${ }^{3}$ \\ ${ }^{1}$ T.F. Gorbachev Kuzbass State Technical University, Vesennyaya str., 28, Kemerovo, 650000 \\ ${ }^{2}$ Prokopyevsk branch of the T.F. Gorbachev Kuzbass State Technical University, Nogradskaya str., \\ 19a, Prokopyevsk, 653033 \\ ${ }^{3}$ West Siberian Industrial Engineering Ltd., Kutuzova str., 39, Novokuznetsk, 654041
}

\begin{abstract}
The present now normative and information base is regulating of the Kuzbass coal seams treatment but is not considering of the mininggeological and mining-engineering conditions for new coal deposits. The analysis of works for the research of the rock pressure manifestation shows that in many cases numerous results require of the practical confirmation in mine conditions directly, and also confirmation by the physical models. This work reflects one of the stages of research on changing the stress-strain state of the massif with the formation of unloading zones, increased rock pressure, and recovery. As an example, the results of the information analysis obtained by means of contour and depth benchmarks on the ventilation drift in the course of the 34 seam treatment at the "Tagaryshskaya" mine are presented. The differences of the analyzed results from the results obtained in the conditions of other mines are established. The values of the drift's roof stratification on the contour and at the distance from the contour of 1.0 to $4.0 \mathrm{~m}$ are given. The revealed maximums of the rock pressure and pressure changes in the hydraulic supports of the complex used for movement are presented. Recommendations on the choice of the anchor's length taking into account the roof stratification size are given. The further research stages on models from equivalent materials at various geometric scales are proposed.
\end{abstract}

\section{Introduction}

In the "Guidelines for the rational treatment of sequence of closed steep and steeply inclined seams of Kuzbass", developed by VNIMI, which have actuality this time, the mininggeological and mining-engineering conditions for new coal deposits (Erunakovskoe, Kazankovskoe etc.) are not taken into consideration. That is why, to compose of the same normative document for these deposits, it's necessary to have mine and laboratory researches in accordance with terms of similarity under simulated testing of the seams on the physical models, including of the stress-strain state researches for the preparatory mine workings. It's

*Corresponding author: oleg_lyubimov@mail.ru 
possible to use the results of the mine preparatory working's roof stress-strain state researches for the choice of the anchor's length, which exceeds the roof stratification size, and also for the practical registration of the rock pressure and pressure changes in the hydraulic supports applied to specific conditions.

There are no clear recommendations on the choice of the anchor's length taking into account the formation of zones of the increased rock pressure in domestic and foreign practice now.

In this regard the rock pressure manifestation researches in domestic conditions and abroad are carried out by complex method, including analytical part, the mine development modeling and the full-scale mine researches.

For example, the article [1] describes the mathematical modeling of a system linking the movement drift over of the longwall.

In the time, when the process of formation of zones of the rock pressure reference ahead of the coalface is studied, the modeling of the extraction area [2-5] is described.

In publications [6 - 11] with respect to local field studies, it was noted that the length of the zones of the rock pressure reference does not exceed $15 \ldots 20 \%$ of the depth of development, and the values of the reference pressure can exceed hydrostatic $2 \ldots 4$ times.

In articles [12-13] the attempt to determine the influence of the coalface moving speed on the nature of the rock pressure manifestation is made. But, for justification of the obtained dependencies, additional researches are needed.

In works [14-15] the opportunity of the connection of the rock pressure manifestation with the relative strain changes in rock massif during treatment of a single seam and seam suits.

So, to obtain new information correcting and justifying of the modern instructions similar named above, the aim is tasked to study the rock pressure manifestations (for example, in the "Tagaryshskaya" mine) with the task of obtaining new data and comparison them with previously known for mine conditions and also with data of the physical modeling researches.

\section{Method of experimental researches}

Researches were conducted on the ventilation and conveyor drifts during mining seam 34-3 (longwall 3) in the presence the undermined seam 35 (the thickness between seams $-80 \mathrm{~m}$ ) and the overmined seam 33 (the thickness between seams $-90 \mathrm{~m}$ ).

When developing seam $34(\mathrm{~m}=2.8 \mathrm{~m}, \mathrm{a}=5-8 \mathrm{deg}, \mathrm{N}=320-340 \mathrm{~m})$ in the longwall $\left(\mathrm{L}_{\mathrm{v}}=250\right.$ $\mathrm{m}, \mathrm{Lpr}=2500 \mathrm{~m}$ ), the complex MCD was used. Excavation of coal was carried out by harvester KSW 460. The immediate roof strata is the siltstone fine-grained $(\mathrm{m}=20,0 \mathrm{~m}, \mathrm{f}=3$ 4). The average speed of the movement of the longwall was $2.5-3.5 \mathrm{~m} /$ day.

Conveyor and ventilation drifts in the roof were anchored with a length of $2.2 \mathrm{~m}$ for 6 anchors at the roof bar of channel No. $20(1=4.4 \mathrm{~m})$, including 2 key anchors (with malleable washers) at the side of the ventilation drift and the 1 key anchor at the side of conveyor drift. Sides of drifts were anchored by SHK anchors with $1.8 \mathrm{~m}$ length, one anchor on the sides with the distance along strike and $1.0 \mathrm{~m}$ in alignment with the roof bars.

The displacement measurements were carried out on the contour and on the distance up to $4 \mathrm{~m}$ from the contour of drifts, on the distance $400 \mathrm{~m}$ from the mounting chamber. The depth benchmarks GR1, GR2, GR3 were placed in alignment with the contour benchmark KR at the distance: GR1 - $1.0 \mathrm{~m}$; GR2 - $2.5 \mathrm{~m}$; GR3 - $4.0 \mathrm{~m}$.

Measuring of the depth and contour benchmark's displacements values was performed according to the VNIMI method. The measurement circuit is represented on fig. 1. 


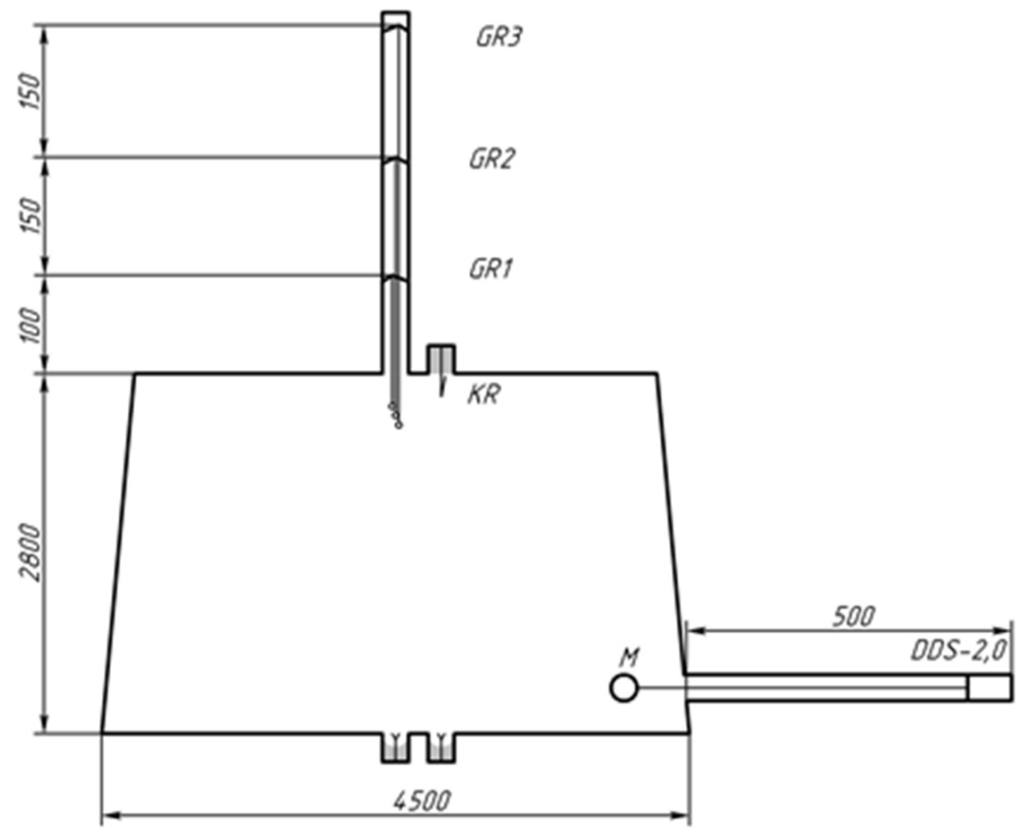

Fig. 1. The measurement circuit in the course of researches.

The contour benchmark was created by drilling the $0.2 \mathrm{~m}$ long hole, a hook was inserted into the wooden wedge from the side of the working's roof for the measuring tool clamping, and a pin in the working's bedrock was inserted into the wood with a recess for fixing the conical part of the measuring tool.

From the depth benchmarks fixed in the bore by spacers, the numbered flexible links with loops for engaging the measuring tool are withdrawn, and there is also a pin in the bedrock with a recess for fixing the conical part of the measuring tool.

Simultaneously the formation of the reference pressure at the bedrock by means of the hole pressure detector DDS-2,0, and also the character of the pressure manifestation in the hydraulic supports at the middle of the longwall were studied. Changes in the reference pressure were recorded with a manometer $\mathrm{M}$.

\section{Results and discussion}

The displacements of contour KR and depth GR1 - GR3 benchmarks on the ventilation drift are represented in table; on the fig. 2 the displacement diagrams are shown. Results are lower by $5-7 \%$ on the conveyor drift. It is quite explainable by lack of availability of the developed area behind of the conveyor drift.

Analysis of the table and diagrams shows, that the contour benchmark's displacements are fixed at the approach of the coalface at $50 \mathrm{~m}$ to observation station and whey are reaching a maximum in alignment with the line of the coalface movement.

Table. 1. The values of the contour and depth benchmark's displacements on the ventilation drift in dependence of the coalface movement.

\begin{tabular}{|c|c|c|c|c|c|c|c|c|c|c|c|c|}
\hline \multirow{2}{*}{$\begin{array}{c}\text { Names of } \\
\text { benchmarks }\end{array}$} & \multicolumn{10}{|c|}{ Distance from the coalface, m } \\
\cline { 2 - 11 } & 50 & 45 & 40 & 35 & 30 & 25 & 20 & 15 & 10 & 5 & 0 & -5 \\
\cline { 2 - 11 } & \multicolumn{10}{|c|}{ Displacements of benchmarks } \\
\hline KR & 1.9 & 5 & 10 & 20 & 29 & 31 & 49 & 77 & 94 & 115 & 119 & 120 \\
\hline
\end{tabular}




\begin{tabular}{|c|c|c|c|c|c|c|c|c|c|c|c|c|}
\hline GR1 & & 2 & 3 & 7 & 12 & 14 & 15 & 35 & 47 & 52 & 55 & 56 \\
\hline GR2 & & & 2 & 3.3 & 5.4 & 6.6 & 7.7 & 17 & 24 & 27 & 28 & 29 \\
\hline GR3 & & & & 1.6 & 2 & 3.3 & 3.6 & 8 & 11 & 14 & 14 & 14 \\
\hline
\end{tabular}

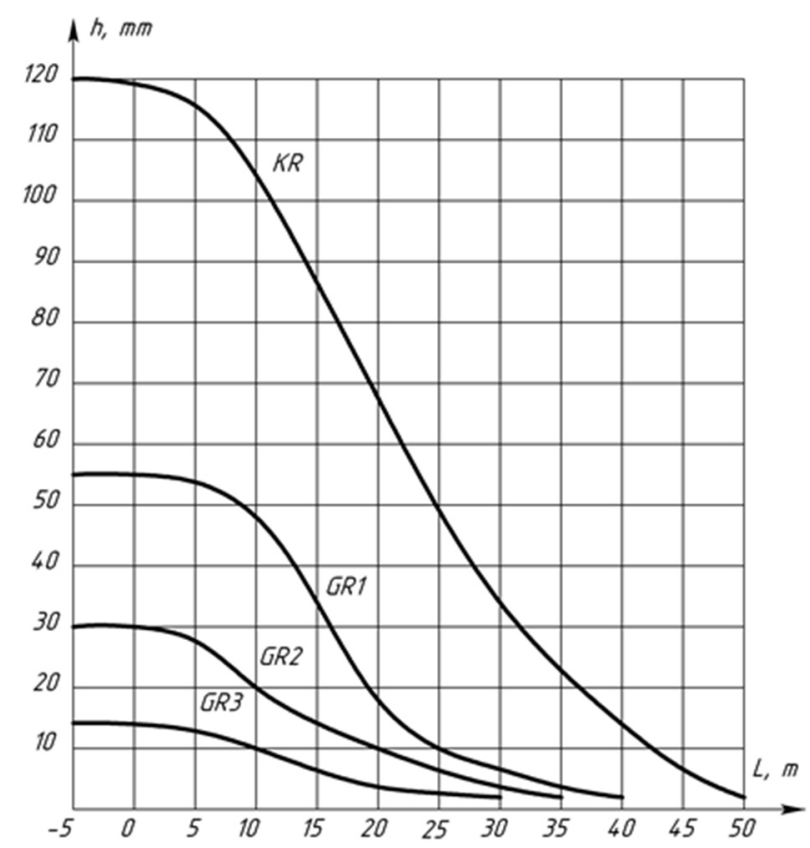

Fig. 2. Diagrams of displacements of contour (KR) and depth (GR) benchmarks.

Displacements of the GR1 depth benchmark on the contour distance $1.0 \mathrm{~m}$ had begun manifest in approach of coalface on $37 \mathrm{~m}$ to measuring point and had reached $55 \mathrm{~mm}$ with the line of the coalface.

Displacements of the GR2 depth benchmark had begun manifest in approach of coalface to measuring point on distance $33 \ldots 35 \mathrm{~m}$ and had reached $28 . .29 \mathrm{~mm}$ with the line of the coalface.

Displacements of the GR3 depth benchmark had begun manifest in approach of the coalface on distance $30 \mathrm{~m}$ and had reached maximum in $14 \mathrm{~mm}$.

The character of change of pressure in hydraulic supports oscillated in limits 10.5 .17.5..10.5 MPa. These oscillations can be explained by the fact that the periodical growth of maximum occurred as secondary caving steps of the immediate roof every $6 \ldots 8 \mathrm{~m}$ (fixed in another publication about developing of this longwall).

Maximum of pressure with concentration factor $\mathrm{K}=2.1$ had manifested at the coalface approach to DDS-2,0 detector on $1.8 \ldots 2.0 \mathrm{~m}$. The small concentration factor value compared with the another author's data $(\mathrm{K}=2.5 \ldots 4.0)$ can be explained by the fact that in this case developed space was constantly filled by collapsed rocks of the immediate roof represented by the siltstone (fulfilled the role of the backfill array).

The existing experience of simulation the treatment of seams on physical models shows that it is practically impossible to simulate the work of the supports with different configurations on small scale models. But it is possible to describe the change in the stressstrain state of the rock massif and the change in the character of the redistribution of the rock pressure in moving of the coalface. Therefore, the idea which has been put for forward researches is: after the modeling on a small scale $(1: 100,1: 200)$ to use the obtained results of the formation of unloading zones, zones of increased rock pressure and damping zones on large-scale models (1:20, 1:30) and simulate step-by-step functioning of supports for further comparative analysis. 


\section{Conclusion}

1. As a result of researches, carried out at the "Tagaryshskaya" mine, new data about the stress-strain state of the rock massif around of the preparatory mine workings on the single seam with the presence of overlying and underlying seams are received.

2. Researches of the rock pressure manifestations shows, that the established data significantly ( $2 \ldots 3$ times) lower than results, which were obtained at other mines with the hard-to-fall roofs.

3. The contour benchmark's displacements can be the basis of recommendations that anchor's length in the same conditions would exceed maximum of the roof stratification and would be about $2.5 \ldots 2.6 \mathrm{~m}$.

4. During researches of character of change in pressure in the hydraulic supports should include the pressure increase as steps of roof collapse (primary and subsequent), applied to specific conditions.

5. In order to clarify the nature of the redistribution of the rock pressure around preparatory mine workings, when they are overmined or undermined, there are not enough the obtained data. To obtain the missing data, an imitation of the treatment of the suit of seams on models from equivalent materials can be provided, with obtaining correction coefficients for the transition from models to real conditions.

6. In developing of normative documents for new Kuzbass deposits it is necessary to spend more additional researches (both full-scale and laboratory on the physical models), so as the separate researches in mine conditions (complex, time-consuming and expensive) are insufficient to justify of the rock pressure manifestation regularity with a wide variety of the mining-geological and mining-engineering conditions.

\section{References}

1. Q. Chen, K. Zhou, T. Long, F. Gao, Journ. of Inst. of Sc. Tech. Inf. of China, 5, 200 (2008)

2. Y. Zhang, Zh. Wan, B. Gu, Ch. Zhou, Therm. Sc., 20, 2149 (2016)

3. L. Barron, Proc. Of $9^{\text {th }}$ Intern. Conf. On Ground Control in Mining, 142 (1990)

4. V. Sotskov, I. Saleev, Min of miner. depos., 4, 165 (2013)

5. V. Sotskov, G. Gusev, Min of miner. depos., 6, 197 (2014)

6. K. Stefan, Gluckauf 1, 50 (2004)

7. K. Erer, A. Heidareh - Zadeh, Min. Sc. and Tech. 3, 191 (1985)

8. P. Lane, Rept. Invest Bur Mines us Dep. Intez 89, 29 (1985)

9. Prediction of shears zones associated with outbursts in coal mines (Lama R.D.S., 1987)

10. L. Fu-Chen, Zh. Wei, S. Ai-hua, El. J. of Geotech. Eng. 18, 1221 (2013)

11. P. Peng-Zhi, J. Rutquist, F. Xia-Ting, Y. Fei, J. Quan, Rock Mech. And Rock Eng. 47, 6 (2014)

12. Z. Bieniawski, Rock mechanics design in mining and tunelling (Rotterdam, 1984)

13. D. Oyler, C. Mark, W. Gale, J. Chen, Performance of Roof Support Under High Stress in U.S. Coal Mine (Littelton, 2004)

14. S. Kostyuk, N. Bedarev, O. Lyubimov, A. Shaikhislamov, E3S Web of Conf. 15, 01009 (2017).

15. R. Scigala, Gosp. Sur. Min., 29, 191 (2013) 
